\title{
Experiência e juventude profissionais no contexto curricular da Universidade Nova: perfil docente frente a proposta de inovação curricular
}

\author{
AMANDA REZENDE COSTA XAVIE ${ }^{(1)}$ \\ MARIA ANTÔNIA RAMOS DE AZEVEDO (2) \\ LÍGIA BUENO ZANGALI CARRASCO ${ }^{(3)}$
}

(1) Doutoranda em Educação pela Universidade Estadual Paulista, na linha de pesquisa Linguagem-ExperiênciaMemória-Formação. Membro do Grupo de Estudos e Pesquisas em Pedagogia Universitária - GEPPU, da UNESP (Rio Claro, sp), registrado no

Diretório do cnpq. Atualmente é Pedagoga da Universidade Federal de Alfenas (UNIFALMG), no Campus Avançado

de Poços de Caldas.Possui graduação em Pedagogia pelo Centro Universitário do Sul de

Minas (2006) e especializaçâo em Gestão Escolar e

Coordenação Pedagógica pela Universidade Gama Filho (20I0). Psicopedagoga pela Faculdade Integrada da Grande Fortaleza (2OI2). Mestre em Educação pela Universidade Estadual Paulista (20I4), na linha de pesquisa Formação de Professores e Trabalho Docente. arezendexavier@hotmail.com
(2) Possui graduação em Pedagogia pela Pontifícia Universidade Católica de São Paulo (1989); Mestrado em Educação pela Universidade Federal de Santa Maria (1997); Doutorado em Educação pela Universidade de Sáo Paulo (2009); e Pós-Doutorado (20II) em Pedagogia Universitária na Universidade do Vale do Rio dos Sinos (Unisinos). É vice-diretora do Instituto de Biociências da Universidade Estadual Paulista UNESP, Campus de Rio Claro. É líder do Grupo de Estudos e Pesquisas em Pedagogia Universitária (GEPPU/UNESP) e membro dos Grupo de

Pesquisa Docência, Formação de Professores e Práticas de Ensino (DOFPPEN/UNESP) e Grupo de Pesquisa em Formação de Professores, Ensino e Avaliação (Unisinos), todos certificados no CNPq. razevedo@rc.unesp.br
(3) Possui graduação em

Pedagogia pela UNESP Universidade Estadual Paulista Júlio de Mesquita Filho Instituto de Biociências (2005).

Pós-Graduação em Gestão

Educacional pelas Faculdades Claretianas de Rio Claro. Mestre em Educação pelo

Programa de Pós-Graduação da Unesp de Rio Claro na linha de pesquisa: Linguagem - Experiência - Memória -

Formação, concentrando

a pesquisa na Pedagogia Universitária. Doutoranda em Educação pelo Programa de Pós-graduação da Unesp de Rio Claro. Diretora de escola desde 20 oro na Rede Municipal de Rio Claro, SP. Desde 2013 atua como formadora do Programa Pacto pela Alfabetização na Idade

Certa (MEC) no Município de Rio Claro.

li_carrasco@yahoo.com.br 


\section{Experiencia y juventud profesionales en contexto curricular de la Universidade Nova: perfil docente frente a la propuesta de innovación curricular}

Palavras-chave. Inovação curricular e pedagógica . Perfil docente - Universidade Nova

Resumo. Este artigo tem o objetivo de retratar o perfil de docentes universitários que têm vivenciado um contexto específico de inovação curricular, o modelo curricular da Universidade Nova. A partir de um estudo qualitativo focalizado, em um campus de uma universidade federal brasileira que nasceu sob a proposta de inovação curricular referida, o presente estudo traz a identificação de uma heterogeneidade na composição do corpo docente de um curso de graduação decorrente do modelo curricular da Universidade Nova, o Bacharelado Interdisciplinar. Evidencia-se que essa heterogeneidade percorre desde a faixa etária dos docentes, até a formação inicial e tempo de experiência na docência, fazendo com que experiência e juventude profissionais coadjuvem em mesmo contexto. Concluímos que a presença de um corpo docente heterogêneo, com diferentes tempos de experiências profissionais, pode contribuir para a efetivação da inovação pedagógica, bem como pode servir de entrave para que mudanças aconteçam na universidade, opções essas que dependerão de como os docentes ressignificarão suas práticas pedagógicas.
Palabras claves. Innovación curricular y pedagógica . Perfil docente · Universidade Nova

Resumen. Este artículo tiene el objetivo de retratar el perfil de docentes universitarios que han vivido un contexto específico de innovación curricular, el modelo curricular de la Universidade Nova. A partir de un estudio cualitativo focalizado, en un campus de una universidad federal brasileña que nació bajo la propuesta de innovación curricular referida, el presente trae la identificación de una heterogeneidad en la composición del cuerpo docente de un curso de graduación derivado del modelo curricular de la Universidade Nova, el Bachillerato Interdisciplinario. Se evidencia que esta heterogeneidad recorre desde el grupo de edad de los docentes, hasta la formación inicial y el tiempo de experiencia en la docencia, haciendo que la experiencia y la juventud profesionales coadyuvan en el mismo contexto. Concluimos que la presencia de un cuerpo docente heterogéneo, con diferentes tiempos de experiencias profesionales, puede contribuir a la efectividad de la innovación pedagógica, así como puede servir de obstáculo para que los cambios ocurran en la universidad, opciones que dependerán de cómo los docentes resignificarán sus prácticas de la educación. 


\title{
Experience and youth professionals in the curricular context of the Universidade Nova: professor profile against the proposal of curricular innovation
}

\author{
Keywords. Curriculum and pedagogical innovation . \\ Professor profile · Universidade Nova
}

\begin{abstract}
This article aims to reflect the profile of university professors who have experienced a specific context of curricular innovation, the curricular model of Universidade Nova. Based on a qualitative study focused on a campus of a Brazilian federal university that was born under the proposed curricular innovation, the present brings the identification of a heterogeneity in the composition of the professors group of an undergraduate course resulting from the curricular model of the Universidade Nova, the Interdisciplinary
\end{abstract}

Bachelor. It is evident that this heterogeneity ranges from the age of the professors, to the initial formation and time of experience in teaching, making experience and youth professionals exist in the same context. We conclude that the presence of a heterogeneous professor's group with different times of professional experience can contribute to the effectiveness of pedagogical innovation, as well as being a barrier to changes in the university, which will depend on how professors will re-signify their practices pedagogical.

O modelo universitário trazido com a proposta da Universidade Nova, derivado do contexto político-educacional recente no Brasil, favorecido pela política de reestruturação e ampliação das universidades públicas federais, conhecido por REUNI e instituído pelo Governo Federal Brasileiro por meio do Decreto $n^{\circ}$ 6096, de 24 de abril de 2007, implica concepções de formação adversas daquelas às quais a universidade está habituada. Requer o entendimento de uma formação generalista, flexível e interdisciplinar como pilares do modelo. Por assim ser, se autodenomina como um modelo de inovação curricular. A Universidade Nova consente que o conhecimento disciplinar, valorizado com o modelo de produção capitalista, que serviu de alicerce para as relações de produção e transmissão do conhecimento na universidade, se tornou insuficiente para dar respostas às exigências da sociedade complexa que se consolidou na contemporaneidade (Almeida Filho, 2008). Assim, aproximam-se da universidade novas concepções, tanto no plano político, quanto no plano epistemológico. 
No plano epistemológico estão as alternativas de organização do pensamento e de produção do conhecimento. Entre essas alternativas estão a interdisciplinaridade, correspondendo à "busca de interfaces e conexões entre disciplinas", e a transdisciplinaridade, compreendida como a "experimentação de trânsito de sujeitos entre campos de conhecimento distintos" (Almeida Filho, 2008:170). No plano epistemológico, verifica-se uma articulação, consciente e proposital, de disciplinas, paradigmas educacionais e de campos do saber. Em termos políticos, a universidade tem que corresponder à sua missão social, na qual a inclusão seja um imperativo e não uma benevolência. Essa é uma questão a ser superada para que se aborde a crise de legitimidade vivida pela universidade, e esta deixe de ser uma instituição para as elites (Sousa Santos, 2008). Isso porque a universidade, enquanto bem público ligado coerentemente com um projeto de nação, ou seja, com um contrato político e social amplo, desdobrado em vários contratos setoriais, sendo um deles o contrato educacional e, dentro deste, o contrato da universidade como bem público (Sousa Santos,2011:56), deve levar em conta sua missão de integração social e política, de inclusão social e defesa da cultura local, de formação humanística e ética, e de formação profissional, na mesma medida em que deve levar em conta sua concepção para a pesquisa e para a produção do conhecimento científico e tecnológico, exigidos pela sociedade globalizada (Almeida Filho, Sousa Santos, 2008; Sousa Santos 2011).

Nesse contexto, a proposta de inovação curricular contida no modelo da Universidade Nova retrata uma nova modalidade de curso de graduação, chamada Bacharelado Interdisciplinar. Os princípios orientadores que regem as estruturas curriculares e acadêmicas que se originam na filosofia da Universidade Nova se modelam sobre a flexibilidade curricular, que busca a superação dos currículos rígidos, reflexos do modelo universitário do século XIX; sobre a autonomia no processo de aprendizagem, pois essa é condição básica para o desenvolvimento de competências e habilidades, em um currículo em que a simples memorização de conteúdos não é suficiente, além de ser elemento fundamental para o desenvolvimento da prática da investigação e, assim, conectar ensino e pesquisa; sobre a articulação disciplinar, para superar a visão fragmentada do conhecimento e construir um currículo interdisciplinar; e sobre a atualização, forma pela qual os projetos pedagógicos devem se manter vivos, para, então, 
contemplarem os avanços científicos e tecnológicos, e as inovações artísticas e culturais na grande área de conhecimento em que se concentra (Almeida Filho, 2008; Brasil, 2010).Sob esses princípios, objetiva a aquisição de uma base de conhecimentos sólida, que subsidia o desenvolvimento de competências cognitivas; objetiva a flexibilização curricular, por meio da liberdade de escolha dos percursos de aprendizagem, para se alcançar uma conseqüente integração disciplinar; objetiva romper com a precoce escolha profissional,postergando-a para um momento de maior maturidade do estudante e possibilitando diminuir os prejuízos individuais e institucionais que essa escolha precoce acarreta, prejuízos estes verificados principalmente na figura da evasão e da desistência (Almeida Filho, 2008; Brasil, 2010).

Observando esse modelo curricular da Universidade Nova, percebemos especificidades formativas que diferem dos cursos tradicionais, aos quais a universidade está habituada. 0 modelo se constrói sobre determinados pilares que sustentam uma formação generalista, que busca o rompimento com padrões curriculares baseados em processos prescritivos de ensino, e que valoriza autonomia e mobilidade. Esse é, portanto, o cenário que se desenha para a docência universitária inserida nesses contextos, e que nos leva a considerar que a prática pedagógica docente precisa ser refletida, no sentido de ser inovada para se tornar coerente com a proposta de inovação curricular.

Logo, temos a inserção de exigências que nos parecem trazer desafios que precisam ser enfrentados pelos docentes que se veem inseridos nesses contextos de inovação curricular.O enfrentamento possivelmente perpassa pela construção de saberes da docência (Cunha, 2006, 2008, 2009), que são os saberes próprios da profissão docente, queextrapolamoslimitesconteudistasdeumconhecimentoespecializadoetécnico, paraabrangerquestões, problemaseobjetosrelacionadosàintegralidadedotrabalhodocente.Sãoplurais e heterogêneos, de naturezas diferentes, relacionados ao currículo, à profissão, à experiência pedagógica, por exemplo, e que podem "potencializar uma formação de qualidade e oportunizar melhores condições de aprendizagem" (Leite, Ramos, 2007:29). Como orienta Carrasco (2016), a socialização de saberes se faz fundamental para essa construção.

Contudo, como tratar o enfrentamento dos desafios sem, previamente, conhecer o docente que os vivencia? Conhecer o cenário em que esses atores 
se inserem parece-nos essencial para entender os desafios que se mostram, entretanto, conhecer os atores é o ponto de partida para quaisquer considerações. Essa questão orientou esse estudo, com vistas a identificar quem são esses docentes inseridos nesses contextos curriculares da Universidade Nova e que têm vivenciado essa nova realidade curricular que traz desafios para a docência. Que perfil compõe o corpo docente inserido nesse modelo curricular?

\section{Os caminhos da pesquisa: de onde estamos falando?}

0 percurso metodológico que sustenta este trabalho se recosta em uma abordagem qualitativa, cujo estudo focalizado ocorreu em um campus avançado de uma universidade federal do estado de Minas Gerais, no Brasil, onde a prática pedagógica do docente está permanentemente envolvida no ambiente de inovação curricular, o que potencializa o estudo.

O lócus foi favorável à realização da pesquisa, uma vez que esse campus foi criado exatamente nas condições de reestruturação e inovação curricular, que constituem o cenário ora exposto. Os cursos desenvolvidos ali se orientam sob o modelo curricular da Universidade Nova, com a oferta de um curso de Bacharelado Interdisciplinar, e sob as diretrizes do REUNI. As contratações do corpo docente se pautaram nas necessidades de um projeto pedagógico interdisciplinar. Desde o ingresso na instituição, o corpo docente que compõe esse campus, em sua maioria, sempre esteve vinculado a essa proposta.

As categorias, que visam retratar o perfil do corpo docente deste estudo focalizado, foram delimitadas a priori, a partir de orientações da literatura, de forma que nos permitissem dialogar com os referenciais sobre a valorização dos saberes pedagógicos na profissão docente, assim como pensar as potencialidades e dificuldades inerentes à sua inserção em um modelo curricular inovador. Os dados foram coletados por meio da aplicação de questionário semiestruturado, e foram olhados à luz dos conhecimentos produzidos no campo da Pedagogia Universitária, cujos pesquisadores expoentes têm-nos ajudado a compreender a temática da inovação curricular e pedagógica no contexto universitário.

Os participantes do estudo foram 10 docentes pertencentes ao quadro profissional do campus, ora apresentado, e que atuam diretamente no curso de 
Bacharelado Interdisciplinar. O critério de seleção da amostra se respaldou na representação dos eixos de conhecimento que compõem o projeto pedagógico do curso, bem como representação de todos os extratos de participação dos professores no programa de desenvolvimento profissional docente da instituição (e que representam, por isso, a preocupação com o processo de formação pedagógica para a docência). Previmos, com essa representação, atingir uma amostra que abrangesse os diferentes perfis docentes que compõem o quadro, e contribuísse, assim, com o objetivo principal deste estudo.

\section{Os docentes inseridos no contexto da inovação curricular: experiência e juventude profissionais atuando em mesmo cenário}

A heterogeneidade da composição do corpo docente pode ser visualizada desde a descriminação de faixa etária -que vai do início da casa dos trinta anos, chegando à casa dos sessenta anos-, até a formação inicial dos docentes, que abarca uma variedade de áreas do conhecimento e diferentes tempos decorridos nessa formação. Esses dados nos apontam que num mesmo contexto de inovação curricular, que exige esforço e mobilização dos docentes, habitam profissionais experientes e jovens professores, iniciantes da carreira docente, ainda que experientes na área profissional específica da formação inicial.

\begin{tabular}{l|l|l|l}
\hline Docente & \multicolumn{1}{l}{ Sexo } & \multicolumn{1}{l}{ Idade } & \multicolumn{1}{l}{ Formação na Graduação } \\
\hline A & M & 47 & Engenharia Elétrica, Bacharelado \\
B & F & 47 & Ciências Jurídicas e Sociais, Bacharelado \\
C & M & 47 & Engenharia Química, Bacharelado \\
D & M & 36 & Ciências Biológicas, Bacharelado e Licenciatura \\
E & F & 32 & Geologia, Bacharelado \\
F & M & 34 & Física, Licenciatura \\
G & F & 32 & Química, Bacharelado e Licenciatura \\
H & M & 32 & Matemática, Licenciatura e Bacharelado \\
I & F & 39 & Engenharia Química, Bacharelado \\
J & F & 62 & Letras, Licenciatura \\
\hline
\end{tabular}

Fonte: Xavier, 2014.

Tabela1. Demonstrativo da caracterização do corpo docente 
Em um modelo curricular em que a interdisciplinaridade é um pilar, entendemos que a conexão entre diversas áreas do conhecimento deve ser valorizada, para que os objetivos da proposta sejam alcançados. E, para tanto, a contemplação dessas diversas áreas do conhecimento deve ser efetiva, reconhecida na formação dos docentes. A essa questão se relaciona a concepção de Gusdorf (1977) sobre ter a interdisciplinaridade o objetivo de não somente integrar o conhecimento, mas também de humanizar a ciência. "A fragmentação do conhecimento desnaturaliza a natureza, por um lado, e desumaniza a humanidade, por outro, ao promover as rupturas entre o conhecimento da natureza e do mundo social" (Philippi Jr. et al., 2011:20). A caracterização observada, acerca dos diferentes campos de conhecimento respaldarem a oferta do modelo curricular, nos demonstra, então, coerência entre a formação dos docentes com a formação que se espera oferecer e desenvolver sob a filosofia curricular da Universidade Nova. Nesse contexto, parece haver espaço para a gama de profissionais que contribuem para o desenvolvimento de um determinado campo de conhecimento, que no caso da pesquisa em questão é a Ciência e Tecnologia. Transitam, no curso, profissionais desde a área das ciências da natureza, da terra e exatas, passando pelas engenharias, até as ciências sociais e humanas. Considerando assim a pluralidade de áreas e campo de conhecimento atuando num mesmo espaço curricular, a faixa etária do corpo docente chama a atenção, pois, em sua maioria, é composta por jovens profissionais, mas também há docentes com significativa maturidade profissional. Essa convivência cotidiana entre jovens e experientes parece muito produtiva, pois, como alerta Cunha (1994), o saber da experiência é um fator que promove a qualificação das práticas pedagógicas. Desta maneira, as relações acadêmicas podem se pautar no apoio dos maduros aos mais jovens, em processo formativo coletivo. No entanto, chama também a atenção o fato de os jovens profissionais já terem alto nível de titulação acadêmica. A observação do nível de titulação que os docentes possuem, aliada ao tempo de formação, indica a preocupação primeira com a especialização, e conseqüente titulação, necessárias para o ingresso na carreira da docência universitária. 


\begin{tabular}{c|l|l}
\hline Docente & Nível de titulação atual & \multicolumn{2}{l}{ Tempo de conclusão da titulação atual } \\
\hline A & Pós-doutorado & 4 anos \\
B & Doutorado & 10 anos \\
C & Doutorado & Não respondeu \\
D & Doutorado & 2 anos \\
E & Doutorado & 4 anos \\
F & Doutorado & 5 anos \\
G & Pós-doutorado & 5 anos \\
H & Doutorado & 5 meses \\
I & Doutorado & 10 anos \\
J & Doutorado & 5 anos \\
\hline
\end{tabular}

Fonte: Xavier, 2014.

Tabela2. Demonstrativo do nível de titulação

Essa especialização é uma tendência destacada em muitos estudos (Cunha, 1998, 2008; Azevedo, 2009; Azevedo e Andrade, 2011). Ao focalizara questão da formação docente para o ensino superior, Fernandes, Bastos e Selbach (2010:129) constatam que os programas de pós-graduação stricto sensu, em níveis de doutorado e de mestrado, "são organizados com uma forma que privilegia a especialização, com ênfase no conhecimento de formação de origem disciplinar e profissional, e na preparação para a pesquisa". A crítica não está na importância da formação para a pesquisa, que contribui para o aprofundamento do campo científico. Ela se deposita no fato de que essa formação não entra em sintonia com outras dimensões que são "necessárias e complexas para a construção de sua profissionalidade - sua identidade de ser professor" (Fernandes, Bastos e Selbach, 2010:130).

A questão nos leva a entender a preocupação primordial com a especialização por parte dos docentes, porque o título do doutoramento é requisito, a princípio, para ingresso no cargo docente, nas universidades federais brasileiras. Nesse sentido, a cobrança por títulos e não pela demonstração de competências profissionais de um educador, seja relativo à área pedagógica ou à perspectiva político-social, é o reforço à situação verificada. E, nessa lógica, perpetua-se a definição e aceitação de que quem sabe fazer, sabe ensinar (Masetto, 2003; Cunha, 2009). Logo, se esse é um valor preservado e valorizado pela universidade, a construção e socialização de saberes para a docência, entre docentes experi- 
mentados e jovens iniciantes na carreira, dificilmente se constitui como prática. A respeito dessa discussão, observamos que todas essas assertivas são vivificadas pelos docentes, vez que, quando questionados sobre sua formação para a docência, respondem que não receberam tal preparo durante seu percurso acadêmico. Quando afirmam que tiveram a formação para a docência, cuidam em ressaltar que esta foi bastante restrita a algumas disciplinas oferecidas no curso de pós-graduação. Assim, a partir da tabelal em que abordamos a formação inicial dos docentes, constatamos que a metade dos docentes do curso possui formação inicial em grau de licenciatura. Isso significa que deveriam demonstrar formação profissional para o exercício da docência. Os docentes chegam a afirmar que, ao cursarem a licenciatura, tiveram disciplinas relacionadas à docência, porém, mesmo nestes casos, há uma lacuna quanto à formação, como é possível perceber nas respostas destacadas.

\begin{tabular}{|c|c|c|}
\hline Docente & $\begin{array}{l}\text { Recebeu formação para a docência durante o percurso } \\
\text { acadêmico (em relação à formação inicial)? }\end{array}$ & $\begin{array}{l}\text { Formação para a docência foi suficiente para } \\
\text { o exercício profissional? }\end{array}$ \\
\hline A & Não & $\begin{array}{l}\text { "Minha formação consiste em docentes que tomei } \\
\text { por modelo [...]" }\end{array}$ \\
\hline B & "Uma disciplina na especialização e uma no mestrado" & Não \\
\hline C & Não & Não \\
\hline D & $\begin{array}{l}\text { "Nas disciplinas de licenciatura, e em um curso de } \\
\text { formação docente (Metodologia e Didática do Ensino } \\
\text { Superior)" }\end{array}$ & $\begin{array}{l}\text { "Avalio que foi suficiente. Muita coisa aprendemos } \\
\text { no decorrer, mas a base foi suficiente sim" }\end{array}$ \\
\hline $\mathrm{E}$ & Não & Não \\
\hline $\mathrm{F}$ & $\begin{array}{l}\text { "Na licenciatura houve uma formação, com matérias } \\
\text { teóricas e práticas, inclusive estágio" }\end{array}$ & $\begin{array}{l}\text { "A formação recebida durante a licenciatura foi } \\
\text { fundamental para a formação do atual professor que sou" }\end{array}$ \\
\hline G & $\begin{array}{l}\text { "Seis unidades curriculares de licenciatura com } \\
\text { realização de estágio" }\end{array}$ & $\begin{array}{l}\text { 1) "Não, os estágios que eu realizei geraram algumas } \\
\text { decepções em relação à prática docente" }\end{array}$ \\
\hline $\mathrm{H}$ & $\begin{array}{l}\text { "Apenas formação para o ensino médio. Para o ensino } \\
\text { superior apenas no setor de pesquisa e ou extensão" }\end{array}$ & "Não, principalmente nos quesitos administrativos" \\
\hline । & "Apenas no mestrado, na disciplina de seminários" & -- \\
\hline $\mathrm{J}$ & $\begin{array}{l}\text { "O ensino na universidade visava repassar ao aluno } \\
\text { o componente teórico das disciplinas, com muita } \\
\text { profundidade, mas deixava para um segundo plano a } \\
\text { prática docente" }\end{array}$ & $\begin{array}{l}\text { "A formação acadêmica que recebi na universidade nem } \\
\text { de longe me preparou para a docência" }\end{array}$ \\
\hline
\end{tabular}

Fonte: Xavier, 2014.

Tabela3. Demonstrativo da formação para a docência 
Azevedo (2009), tendo analisado especificamente o caso das licenciaturas, ergue apontamentos que são facilmente aplicáveis à questão a qual estamos nos referindo. A autora constata que ocorre, na formação de professores, a valorização da formação específica em detrimento aos aspectos pedagógicos. Essa condição, em muito, fortalece a desarticulação entre conteúdo específico e formação pedagógica. Conclui a autora que "a valorização exacerbada desse tipo de racionalidade impregnou a formação de professores que pendiam muito mais para a construção de uma identidade profissional nos moldes de um sujeito capacitado para realizar tarefas" (Azevedo, 2009:24), em vez de construir um profissional competente em nível técnico e político, de tal forma que sua prática seja condizente com a realidade histórica e social vigente (Azevedo, 2009).

Nessa direção, e com atenção às respostas, percebemos que há, de modo geral, uma manifesta insatisfação com a formação para a docência, visto que apenas dois docentes julgaram sua formação suficiente para a atuação profissional. Assim, frente à insuficiência da formação para o exercício profissional da docência, um ponto que nos chama atenção é a resposta do Prof. A, que explicita a internalização do habitus como ferramenta de formação para a docência. Essa manifestação nos expõe ao ciclo de reprodução que se realiza nas relações acadêmicas (Cunha, 1998). Estudos apontam que é de sua história, enquanto alunos, que os professores reconhecem sofrer maior influência. Por sua vez, "esta influência se manifesta na tentativa de repetir atitudes consideradas positivas" (Cunha, 1994:159). Embora presente na prática pedagógica, acreditamos que a reprodução não deva conduzir unicamente o exercício profissional da docência; pelo contrário, a base para a prática docente deve se alicerçar na construção e reconfiguração de saberes, que tornam o profissional apto a enfrentar os desafios da profissão.

Tendo como norte a construção de saberes para a docência, assumimos com Cunha (2006) que a formação docente se constitui dessa construção.Portanto, a observação do recorte aqui delimitado nos permite atentar para uma categoria desses saberes: os saberes da experiência. 


\begin{tabular}{|c|c|c|c|c|c|c|c|c|c|c|}
\hline Docente & A & B & C & D & E & $F$ & G & H & I & $J$ \\
\hline $\begin{array}{l}\text { Tempo de } \\
\text { experiência na } \\
\text { docência }\end{array}$ & 28 anos & 32 anos & 23 anos & 8 anos & 4 anos & 5 anos & 2 anos & 7 anos & 4 anos & 42 anos \\
\hline $\begin{array}{l}\text { Tempo de } \\
\text { experiência } \\
\text { na docência } \\
\text { universitária }\end{array}$ & 28 anos & 17 anos & 23 anos & 7 anos & 4 anos & 5 anos & 1 ano & 5 anos & 4 anos & 20 anos \\
\hline $\begin{array}{l}\text { Tempo de } \\
\text { experiência na } \\
\text { docência do BI }\end{array}$ & $\begin{array}{l}3,5 \\
\text { anos }\end{array}$ & $\begin{array}{l}9 \\
\text { meses }\end{array}$ & 5 anos & 1 ano & $\begin{array}{l}10 \\
\text { meses }\end{array}$ & 5 anos & 1 ano & 3 anos & $\begin{array}{l}3,5 \\
\text { anos }\end{array}$ & 5 anos \\
\hline
\end{tabular}

Fonte: Xavier, 2014.

Tabela 4. Demonstrativo do tempo de experiência na docência

Ora, se assumimos que os saberes são construídos podemos também assumir que a socialização fundamentada das experiências contribui nessa construção.O que se imagina, então, é que os docentes experientes compartilhem suas experiências com os docentes mais jovens, num movimento de aproximação que contribui para a construção de saberes. São estratégias de formação que potencializam os saberes, quando professores experientes se põem a serviço da orientação, tutoria e acompanhamento de professores jovens na docência (Cochram-Smith, 2012; Cunha e Zanchet, 2010). São movimentos de partilha, de troca de saberes entre profissionais que possuem o mesmo objetivo (Carrasco, 2016:173). No cenário do estudo, essa condição parece propícia para que essa lógica seja adotada, visto que se observam profissionais com grande tempo de experiência na docência (de 23 a 42 anos de experiência) e profissionais com pouco, ou muito pouco, tempo de experiência na docência (de 02 anos a 08 anos).

Ademais, se tomarmos como fundamento de auxílio da análise o ciclo de vida profissional docente proposto por Huberman (2000), encontramos no recorte do modelo curricular estudado todas as fases que compõem tal ciclo: a entrada na carreira (de 1 a 3 anos de profissão); a estabilização (de 4 a 6 anos); a experimentação ou diversificação (de 7 a 25 anos); a serenidade e distanciamento afetivo (de 25 a 35 anos); e a preparação para a aposentadoria (35 a 40 anos de profissão). Essa representação de todas as fases 
do ciclo de vida profissional docente torna possível que diferentes práticas pedagógicas se desenvolvam no exercício da docência, nesse contexto curricular da Universidade Nova. Afinal, profissionais experientes e jovens docentes coabitam o mesmo espaço e compartilham o mesmo contexto. Essas práticas podem ser provisórias ou consolidadas pelo saber da experiência, bem como podem representar situações de entusiasmo, pela condição de iniciante na profissão; podem representar estabilidade ou distanciamento, também a depender do tempo de experiência. Podem refletir ações de buscas e descobertas, ou ações cristalizadas e arcaicas, que convivem e, possivelmente, se influenciam mutuamente, em um mesmo espaço curricular.

Entretanto, engendrado o cenário, ao tomar-se em observação a relação do tempo de experiência no modelo curricular da Universidade Nova, verificase que não há uma diferença significativa entre os tempos de experiência. Essa condição decorre do fato de que as propostas de inovação curricular da Universidade Nova são bastantes recentes. Destarte, muito em função da atual expansão das universidades, que criou bastantes vagas para o cargo de docente universitário, o tempo de experiência na docência torna-se quase equivalente ao tempo de inserção na docência no modelo curricular inovador da Universidade Nova. Essa verificação nos permite aferir que não há expressiva experiência profissional na docência, quando construída pela sua inserção em tal modelo curricular.

Nesse sentido, como o próprio Huberman (2000) aponta, entendemos que não há regra para o estabelecimento das práticas docentes, de modo engessado à fase da vida profissional. Dessa maneira, a questão do tempo de experiência no modelo curricular da Universidade Nova pode contribuir para a maximação, tanto das potencialidades como dos desafios da docência, no interior desse modelo. Considerando que não há outra proposta curricular no campus em que tais docentes atuam, parece-nos possível compreendermos que estes poderão, de uma forma peculiar, se verem todos na fase da entrada ou da estabilização do ciclo profissional. E, uma vez considerando-se todos na fase inicial da carreira, o entusiasmo e a mobilização para a inovação pedagógica podem ser potencializados, ampliando os resultados e sucesso do grupo. 


\section{Algumas Considerações}

Este estudo não se propôs a analisar as práticas pedagógicas dos docentes inseridos em contexto de inovação curricular. Antes, objetivou identificar os docentes que vivenciam esse contexto, a partir de um estudo focalizado de um modelo de inovação curricular que traz desafios inerentes à docência. Nesse contexto, muito em decorrência das políticas de fomento do modelo curricular, verificam-se num mesmo espaço profissional docentes experientes e jovens, compartilhando os mesmos desafios.

Ora, o contexto curricular inovador, que envolve o trabalho docente de jovens professores, se caracteriza, por si só, como desafiador e instigante, porque decorre do fato de que, na organização da ação profissional estes professores entendem que basta o domínio de um determinado conhecimento para que se reconheçam professores universitários. Essa percepção se perpetua na crença de que os docentes universitários necessitam apenas saber pesquisar para que seja legitimado o saber ensinar. Essa concepção se pronuncia na formação inicial dos jovens professores universitários.

Consideramos, entretanto, que as diferentes experiências de formação e de vivências, que fazem com que experiência e juventude profissionais coadjuvem em mesmo contexto curricular, sejam um fator favorável para contribuir com a efetivação da inovação pedagógica, se adotada a lógica da construção e socialização de saberes da docência, em permanente aproximação dos experientes aos jovens docentes. Essa coexistência dos perfis em um mesmo modelo de inovação curricular, aproximados pela construção e troca de saberes da docência, pode ser um caminho para conduzir a novas concepções da profissão, no sentido de valorização dos processos de aprender e de ensinar na universidade. Do contrário, as distâncias de área, de formação e de experiência profissional e de vida, podem servir de entrave às mudanças na universidade. Assim, é preciso considerar que a prática pedagógica é em muito influenciada por elementos que se alocam ao longo do percurso e desenvolvimento profissional. Saberes curriculares, profissionais e experienciais (Cunha, 2007), contribuem para a definição da prática pedagógica que regerá a atuação do docente. A construção desses saberes modifica o perfil profissional ao longo da trajetória na carreira, o que nos leva a entender que conferirão ao grupo o desafio de promover a ressignificação de suas práticas pedagógicas, em um processo que se consolida coletivamente. 
Referências bibliográficas

Almeida Filho, Naomar de; Sousa Santos, Boaventura (2008). A Universidade no século XXI: Para uma Universidade Nova. Coimbra: Edições Almedina.

Azevedo, Maria Antônia Ramos de. (2009). Os saberes de orientação dos professores formadores: desafios para ações tutoriais emancipatórias. (Tese de Doutorado). São Paulo: USP.

Azevedo, Maria Antônia Ramos de; \& Andrade; Maria de Fátima Ramos de. (2011). O papel da interdisciplinaridade e a formação do professor: aspectos histórico-filosóficos. Educação Unisinos, v. 15, n. 3, 206-213.

Brasil. Ministério da Educação (2010). Referenciais orientadores para os Bacharelados Interdisciplinares e similares. Brasília: MEC.

Carrasco. Lígia Bueno Zangali (2016). Assessorias pedagógicas das universidades estaduais paulistas: concepções dos espaços institucionais de formação docente universitário. (Dissertação de Mestrado). UNESP, Rio Claro.

Cochran-Smith, Marilyn. (2012). A tale of two teachers: learning to teach over time. Kappa Delta Pi Record, 48:3, 108-122.

Cunha, Maria Isabel da (1994). O bom professor e sua prática. Campinas: Papirus.

(1998).o professor universitário na transição de paradigmas. Araraquara: JM Editora.

(Org.). (2007). Reflexões e práticas em pedagogia universitária. Campinas: Papirus.

(2008). Inovações Pedagógicas: o desafio da reconfiguração de saberes na docência universitária. São Paulo: Cadernos Pedagogia Universitária USP.
(2009). Inovações Pedagógicas: o desafio da reconfiguração de saberes na docência universitária. In: Pimenta, Selma Garrido; Almeida, Maria Isabel (Org.). Pedagogia Universitária (pp. 211-236). São Paulo: EdUSP.

Cunha, Maria Isabel da \& Isaia, Silvia Maria de Aguiar. (2006). Professor da Educação Superior. In: Morosini, Marilia Costa (Ed. Chefe). Enciclopédia de Pedagogia Universitária: Glossário (pp. 351-352). Brasília: INEP/MEC/RIES.

Cunha, Maria Isabel da; \& Zanchet, Beatriz Maria Boéssio Atrib. (2010). A problemática dos professores iniciantes: tendência e prática investigativa no espaço universitário. Educação, Porto Alegre, v. 33, n. 3, 189-197.

Fernandes, Cleoni Maria Barboza; Bastos, Amélia Rota Borges \& Selbach, Paula Trindade da Silva (2010). Cursos e Disciplinas de Formação Pedagógica do Professor Universitário. In: Cunha, Maria Isabel da (Org.). Trajetórias e Lugares de Formação da Docência Universitária: da perspectiva individual ao espaço institucional (pp. 125-146). Araraquara: Junqueira \& Marin. Brasília: CAPES, CNPq.

Gusdorf, George (1977). Passé, présent, avenir de la recherche inerdisciplinaire. Revue internacionale des sciences sociale, v. 29, n. 4, 627-649.

Huberman, Michael (2000). O ciclo de vida profissional dos professores. In: Nóvoa, Antônio (Org.). Vidas de professores (pp. 31-61).Porto: Porto Editora.

Leite, Carlinda;\& Ramos, Katia (2007). Docência Universitária: análise de uma experiência de formação na Universidade do Porto. In: Cunha, Maria Isabel da (Org.). Reflexões e práticas em pedagogia universitária. Campinas: Papirus. 
Masetto, Marcos Tarciso (2003). Competência pedagógica do professor universitário. São Paulo: Summus. Philippi JR, Arlindo et al (2011). Interdisciplinaridade em ciência, tecnologia \& inovação (pp. 3-68). Barueri: Manole.

Sousa Santos, Boaventura de (2011). A Universidade no século XXI: para uma reforma democrática e emancipatória da Universidade. São Paulo: Cortez

Xavier, Amanda Rezende Costa. (2014). Universidade Nova: desafios da prática pedagógica numa perspectiva interdisciplinar. (Dissertação de Mestrado). UNESP: Rio Claro. 